\title{
Manajemen Kaderisasi dalam Mencetak Kader Organisasi Militan
}

\author{
Moh. Nur Cholis \\ Universitas Islam Negeri Maulana Malik Ibrahim Malang \\ e-mail: mncsmpia@gmail.com
}

\begin{abstract}
Regeneration is continuation of the organization. Cadre is the heart of the organization, where the good and the lasting of organization depends on how seriously the organization performs cadre. From the vision of STAI Luqman Al-Hakim Surabaya, it can be seen that one of the outgoing profiles of this institution is the birth of scholars who are cadres. This study aims to reveal the conceptual strategy of planning, implementing and evaluating cadre at STAI Luqman Al-Hakim Surabaya towards the birth of a cadre of militant organizations in the Hidayatullah Organization. This study uses a qualitative descriptive approach based on case studies. Data collection is done by in-depth interviewing, documentation and observation techniques. Starting to sort the data to interpret the findings in the field by trianggulation. The results of this study indicate that: (1) Planning the concept of building militant cadres is done by (a) Formulating the cadre objectives that are in accordance with the vision of STAI Luqman Al-Hakim Surabaya, (b) Determining patterns of cadre formation, (c) Implementing resource management, (2) Strategy for implementing cadre in building militant cadres (a) Strengthening the spirit of struggle, following social actions, contextual learning, incorporating systematics of revelation, incorporating material on the insights of the Islamic movement, (b) Determining stages of cadre formation in accordance with values systematics revelation manhaj value, (c) Conducting supervision and evaluation through logical order and consequences, (d) Determining alumni profile, (3) Evaluate cadre strategies, (a) Record alumni engagement, (b) Record testimonials from alumni cadres, (c) Record alumni user testimonials.
\end{abstract}

Keywords. Building Cadre; Militant Organization

Abstrak. Kaderisasi menjadi proses bagi eksistensi dan kelanjutan dalam sebuah organisasi. Pengkaderan adalah jantungnya organisasi, dimana baik buruknya dan langgengnya organisasi, tergantung dari seberapa serius pelaku organisasi tersebut untuk merencanakan dan melaksanakan strategi pengkaderan. Penelitian ini bertujuan untuk mendeskripsikan strategi konsep perencanaan, pelaksanaan dan evaluasi pengkaderan di STAI Luqman Al-Hakim Surabaya terhadap lahirnya kader organisasi militan di Organisasi Hidayatullah. Pendekatan penelitian ini menggunakan kualitatif deskriptif berbasis studi kasus. Pengumpulan data melalui wawancara mendalam kepada ketua, wakil ketua, dosen, tenaga administrasi dan mahasiswa serta dokumentasi kelengkapan administrasi. Sedangkan untuk menganalisis data deskriptif yaitu dengan memilah data hingga menginterpretasikan hasil temuan di lapangan. Selanjutnya dilakukan proses triangulasi sumber. Hasil penelitian ini menunjukkan bahwa: (1) Perencanaan konsep membangun kader militan dilakukan dengan (a) Perumusan tujuan pengkaderan yang sesuai dengan visi STAI Luqman Al-Hakim Surabaya, (b) Menentukan pola pembinaan kader, (c) Melaksanakan manajemen pengelolaan sumberdaya, (2) Pelaksanaan pengkaderan dalam membangun kader militan (a) Perkuat spirit perjuangan, mengikuti aksi-aksi sosial, pembelajaran konstekstual, memasukkan materi manhaj sistematika wahyu, memasukkan materi wawasan pergerakan Islam, (b) Menentukan tahapan pengkaderan per- jenjang sesuai 
dengan nilai-nilai manhaj sistematika wahyu, (c) Melakukan pengawasan dan evaluasi lewat tata tertib dan konsekuensi logis, (d) Menentukan profil alumni, (3) Evaluasi strategi pengkaderan, (a) Mendata kiprah alumni, (b) Mendata testimoni hasil pengkaderan dari alumni, (c) Mendata testimoni pengguna alumni.

Kata Kunci. Membangun Kader; Organisasi Militan

Copyright (C JMPI: Jurnal Manajemen Pendidikan Islam. All Right Reserved.

This is an open access article under the CC BY-NC-ND license

(http://creativecommons.org/licenses/by-nc-nd/4.0/).

\section{A. PENDAHULUAN}

Dalam sebuah organisasi, kaderisasi menjadi hal yang sangat penting bagi eksistensi dan kelanjutan organisasi. Pengkaderan adalah jantungnya organisasi, dimana baik buruknya dan langgengnya organisasi, sangat tergantung dari seberapa serius pengurus organisasi tersebut melaksanakan pengkaderan. Ketika dalam suatu organisasi pengurus tidak serius dalam melaksanakan pengkaderan secara sistematis, berjenjang, berkelanjutan dan masif, organisasinya akan mati secara perlahan-lahan. Hal tersebut disebabkan minimnya jumlah kader dan minimnya kualitas kader (Rusydi, 2014). Organisasi akan tetap eksis manakala kader penerus visi organisasi itu terpenuhi dengan cukup. Oleh sebab itu pemimpin diharapkan mampu untuk mendayagunakan kemampuan untuk menggerakkan unsur-unsur yang ada di dalam organisasi (An-Nisa': 59).

Hidayatullah sebagai salah satu organisasi Islam di Indonesia tergolong masih sangat muda, berdiri pada 7 Januari 1973 di Balikpapan Kalimantan Timur yang prakarsai oleh Allahuyarham Ustadz Abdullah Said. Walaupun secara usia organisasi masih muda namun saat ini telah mempunyai cabang yang tersebar di seluruh wilayah Nusantara. Awal dari organisasi ini adalah berbentuk Yayasan Pondok Pesantren, namun karena tuntutan zaman sepeninggal Ustadz Abdullah Said pada tahun 2000 dalam Musyawarah Nasional yang pertama, Hidayatullah bermetamorfosa menjadi Organisasi massa (Ormas) Islam yang berkantor pusat di Jakarta. Dalam perkembangannya, pertumbuhan organisasi sangat pesat, ditandai dengan ekspansi pembukaan cabang di seluruh Indonesia hanya dalam waktu 40 tahun. Hal ini tidak terlepas dari pengkaderan perintis awal dalam menyiapkan dan menyakinkan kaderkadernya berangkat dan berjuang untuk membuka cabang baru Hidayatullah di seluruh Nusantara. Menurut Kurniawan (2016) kader adalah orang yang telah dilatih dan dipersiapkan dengan berbagai ketrampilan dan disiplin ilmu, sehingga memiliki kemampuan yang di atas rata-rata orang umum.

Pesantren Hidayatullah Surabaya sebagai salah satu cabang Hidayatullah adalah yayasan yang bergerak dalam bidang Pendidikan, Dakwah dan Sosial yang berdiri pada tahun 1987 dan sampai sekarang berkembang dengan pesat. Dalam bidang Dakwah mengembangkan wilayah dakwah dengan membuka cabang-cabang baru di seluruh kota Kabupaten di Jawa \& Nusa Tenggara. Tumbuhnya cabang-cabang baru tersebut menuntut Pesantren Hidayatullah Surabaya mempersiapkan para da'i dan kyai yang siap diterjunkan ke daerah-daerah untuk membina umat di daerahnya masing-masing.

Berangkat dari latar belakang masalah di atas itulah, maka para pendiri pesantren mendirikan Pendidikan Tinggi Islam (PTI), pada tahun 1994 sebagai lembaga pendidikan dan pengkaderan yang menggodok calon-calon da'i dan kyai. Melihat 
perkembangan zaman, tuntutan sosial dan prospek output mahasiswa, serta peluangnya untuk dapat mengikuti program pendidikan yang lebih tinggi (S2 \& S3) mengharuskan PTI pada tahun 1997 berubah namanya menjadi STAIL (Perguruan tinggi Tinggi Agama Islam Luqman Al-Hakim). Mahasiswa dididik dengan sistem berasrama di pondok pesantren atau boarding School. Menurut Rizkiani (2012) peran pendidikan pembiasaan melalui suatu sistem boarding school dalam penanaman karakter peserta didik, yang pada akhirnya akan membentuk peserta didik yang berkarakter dan menjadi generasi penerus bangsa menjadi penting.

Mahasiswa yang sudah selesai diwisuda langsung ditugaskan ke beberapa kota/kabupaten di Indonesia untuk merintis cabang baru Hidayatullah atau memperkuat cabang Hidayatullah yang sudah ada. Sehingga ikut mengembangakan organisasi Hidayatullah yang tersebar diseluruh kabupaten/kota di Indonesia. Berdasarkan dari hasil pengkaderan yang mampu melahirkan kader yang siap ditugaskan ke daerah mana saja dengan prinsip "sami'na wa 'atho'na" ini, perlu diteliti tentang bagaimana strategi perencanaan dan pelaksanaan proses pengkaderan yang telah dilaksanakan di STAI Luqman Al-Hakim Surabaya dalam segi konsep, strategi, serta evaluasinya dalam membangun kader militan di organisasi Hidayatullah secara nasional.

\section{B. METODE}

Penelitian mengungkap strategi pengelola STAI Luqman Al-Hakim Surabaya dalam membangun kader militan di organisasi Hidayatullah secara nasional, untuk itu peneliti mengungkap tentang peristiwa-peristiwa yang diamati, mengkaji dokumen lembaga, serta apa yang diungkapkan para pengelola STAI Luqman Al-Hakim Surabaya tentang apa yang mereka lakukan dalam proses mencetak kader organisasi Hidayatullah. Untuk mencapai tujuan ini digunakan pendekatan penelitian kualitatif deskriptif berbasis studi kasus.

Sumber data dari penelitian ini dibedakan menjadi dua macam, yakni manusia dan bukan manusia. Sumber data manusia berfungsi sebagai subjek atau informasi kunci dan data yang diperoleh bersifat lunak, informasi kunci penelitian ini meliputi: ketua STAI Luqman Al-Hakim, Pembantu ketua I (bidang akademik), Pembantu ketua II (bidang administrasi umum), Pembantu ketua III (bidang kemahasiswaan), pengasuh, para dosen dan mahasiswa. Sedangkan sumber data yang bukan manusia berupa dokumen yang relevan dengan fokus penelitian yang meliputi, gambar, foto, catatan dan tulisan yang ada kaitannya dengan fokus penelitian. Data yang berasal dari data bukan manusia diperoleh melalui dokumen yang bersifat hard. Pengumpulan data dilakukan dengan teknik wawancara mendalam, dokumentasi dan observasi. Upaya menganalisa data dilakukan dengan teknik analisis data deskriptif, mulai memilah data hingga menginterpretasikan hasil temuan di lapangan. Sumber data utama dalam penelitian kualitatif adalah kata-kata dan tindakan selebihnya adalah data tambahan seperti dokumen dan observasi. Analisis data dilakukan dengan cara melakukan reduksi data, menyajikan data, dan melakukan penarikan kesimpulan. Untuk menjamin keabsahan temuan penelitian digunakan triangulasi sumber data dan teknik pengumpulan data. 


\section{HASIL DAN PEMBAHASAN}

\section{Konsep Perencanaan Pengkaderan di STAI Luqman Al-Hakim - Pesantren Hidayatullah Surabaya}

Hasil penelitian menunjukkan bahwa sebelum mengkonsep pengkaderan di STAI Luqman Al-Hakim Surabaya, ketua STAI Luqman Al-Hakim telah merumuskan tujuan dari pengkaderan yang diambil dari Visi STAI Luqman Al-Hakim Surabaya, yaitu menghasilkan sarjana kader, leader dan profesional di bidang pendidikan, dakwah dan ekonomi syariah. Kader disiapkan untuk menjadi generasi pelanjut estafeta kepemimpinan organisasi Hidayatullah dan ekspansi dakwah Hidayatullah di Indonesia. Untuk itu mereka dibekali dengan ketrampilan memimpin dan keahlian ilmu-ilmu umum dan diniyah serta penanaman nilai-nilai sistematika wahyu dalam setiap kegiatan mahasiswa sebagai manhaj perjuangan Hidayatullah. Menurut Arifin (2014) Kaderisasi adalah mempersiapkan calon-calon (embrio) yang siap melanjutkan tongkat estafet perjuangan sebuah organisasi.

Untuk mewujudkan tujuan tersebut, maka perlu dibuat pola pembinaan kader yang merupakan cara untuk menentukan alternatif terbaik dalam menghasilkan kader yang militan. STAI Luqman Al-Hakim Surabaya mempunyai dua kampus, yaitu kampus I yang ada di Surabaya untuk mahasiswa semester III-VIII dan kampus II yang ada di Panceng - Gresik untuk semester awal, yaitu semester I-II. Mahasiswa semester I-II dipisah seperti ini untuk memudahkan mahasiswa baru di angkatan pertama terbentuk pembiasaan berbahasa Arab dan Inggris. Nurkholis (2017) menyatakan pembelajaran Bahasa Arab di pesantren adalah suatu keharusan, karena bahasa yang dipakai dalam kitab-kitab terdahulu berbahasa Arab, ritual ibadah yang dilakukan sehari-hari juga dengan bahasa Arab. Pesantren adalah satu-satunya lembaga pendidikan yang mempelajari bahasa Arab pada era awal perkembangan agama Islam, bahkan hingga saat ini.

Selain itu tujuan angkatan pertama ditempatkan khusus di kampus II adalah untuk melatih kemampuan tahfidznya sebelum masuk ke tahun ke III-VIII di Surabaya. Menurut Zein (1985) Al-Qur'an adalah kitab suci bagi pemeluk agama Islam, sebagai pedoman hidup dan sumber-sumber hukum, tidak semuanya manusia sanggup menghafal dan tidak semua kitab suci dapat dihafal kecuali kitab suci al-Qur'an dan hamba-hamba terpilihlah yang sanggup menghafalkannya.

Pola pembinaan pengkaderan mahasiswa secara umum terbagi menjadi 2, yaitu pemberian materi muatan kognitif dan kegiatan pengkaderan lewat kehidupan berasrama. Muatan materi kognitif berupa pembekalan secara ilmiyah tentang materimateri keprodian dan diniyah serta penanaman materi manhaj perjuangan Hidayatullah yaitu sistematika wahyu. Sedangkan kegiatan pengkaderan di asrama mahasiswa berupa desain kehidupan Islami yang terjadwal mulai bangun tidur sampai tidur kembali semuanya mengandung nilai-nilai pengkaderan. Muatan kognitif bertujuan untuk membekali intelektual mahasiswa khususnya dalam ilmu umum dan diniyah, sedangkan kegiatan asrama mahasiswa membentuk pembiasaan hidup Islami.

Pesantren (boarding) bisa dikatakan lebih intens dari non pesantren. Hal tersebut disebabkan karena kehidupan yang ada di pesantren berjalan 24 jam penuh dari bangun tidur hingga tidur lagi. Dan semua kegiatan dikonsep agar dapat membentuk karakter yang harus dimiliki oleh seorang muslim sejati. Beberapa kebijakan yang umumnya dilaksanakan di semua pesantren yaitu: sholat berjamaah, kajian kitab, organisasi santri, muhadharah dan praktik dakwah lapangan (Rahmawati, 2016). Hal 
ini sesui dengan yang diterapkan di STAI Luqman Al-Hakim Surabaya yang mana mahasiswa wajib tinggal dan mengikuti kegiatan di asrama.

\section{Strategi pelaksanaan pengkaderan dalam membangun kader yang militan di STAI Luqman Al-Hakim - Pesantren Hidayatullah Surabaya}

Untuk menentukan strategi pengkaderan, ketua STAI Luqman Al-Hakim Surabaya melakukan analisis internal dan analisis eksternal. Hasil dari pengamatan oleh ketua STAI Luqman Al-Hakim Surabaya menemukan bahwa kekuatan lembaga diantaranya adalah mahasiswa berasrama dan tinggal di lingkungan pesantren yang kondusif. Selain itu juga didukung dengan murobbi yang kompeten dan tinggal di lingkungan pesantren. Beberapa murobbi dan dosen sebagian besar adalah alumni STAI Luqman Al-Hakim yang lebih menjiwai dalam pengkaderan, karena pernah merasakan menjadi mahasiswa di STAI Luqman Al-Hakim. Sarana prasana juga mendukung, seperti masjid, ruang perkuliahan serta aula yang representatif. Beberapa mahasiswa senior juga dilibatkan dalam kepengasuhan. Data pelaporan kegiatan mahasiswa juga berbasis IT, sehingga lebih cepat, mudah dan akurat. Menurut Rosenberg (2001), dengan pemanfaatan ICT dalam dunia pendidikan telah terjadi lima pergeseran dalam proses pembelajaran yaitu: (1) dari pelatihan ke penampilan, (2) dari ruang kelas ke di mana dan kapan saja, (3) dari kertas ke "on line" atau saluran, (4) fasilitas fisik ke fasilitas jaringan kerja, (5) dari waktu siklus ke waktu nyata.

Maksud dari mahasiswa diasramakan ini juga memudahkan dalam proses pembinaan kader. Karena pengasuh dapat membimbing dan memantau mahasiswa selama 24 jam. Hal ini sesuai dengan filosofi nabi ibrahim yang diperintahkan Allah untuk meninggalkan istri dan anaknya di suatu lembah yang jauh dari pemukiman. Ismail sebagai seorang kader yang didik oleh hajar dan Ibrahim di tempat yang asing supaya tidak terkontaminasi dengan budaya jahiliyah sebagaimana di jelaskan dalam QS Ibrahim ayat 37.

Selain kekuatan yang dimiliki STAI Luqman Al-Hakim Surabaya juga memiliki kelemahan, yaitu secara kuantitas kurang, baik mahasiswa maupun dosennya. Hal ini karena mahasiswa yang berasrama diberi beasiswa penuh, sehingga penerimaan mahasiswa berdasarkan budget dana yang ditentukan oleh organisasi. Selain itu juga karena beberapa struktural STAI Luqman Al-Hakim rangkap jabatan, sehingga tidak bisa penuh di kampus. Menurut Harahap (2000) rangkap jabatan akan menimbulkan benturan kepentingan, rangkap jabatan juga berkemungkinan menimbulkan hambatan kinerja karyawan, karena setiap divisi memiliki tugas yang berbeda dan dikerjakan oleh satu orang maka hal tersebut dapat mengganggu kerja karyawan yang merangkap jabatan tersebut.

Sedangkan analisis eksternal yakni analisis yang mengarah pada lingkungan di luar lembaga. Hasil pengamatan mengenai lingkungan eksternal terhadap peluang, yakni STAI Luqman Al-Hakim mendapat dukungan penuh dari pihak pesantren Hidayatullah Surabaya. Adanya para donator yang mendonasikan hartanya lewat Unit Pelayanan Zakat (UPZ) untuk mendanai operasional STAI Luqman Al-Hakim. Pemerintah juga memberikan kemudahan bagi perguruan tinggi swasta untuk merger dengan perguruan tinggi lain di bawah naungan Hidayatullah untuk menjadi sebuah universitas. Selain itu citra STAI Luqman Al-Hakim di organisasi Hidayatullah secara nasional sangat bagus, terbukti permintaan kader dari cabang-cabang Hidayatullah di seluruh Indonesia lebih banyak dari pada jumlah kader yang akan ditugaskan, karena 
mereka sudah merasakan manfaatnya. Hal ini sesuai dengan yang disampaikan Merdekawati (2015) bahwa salah satu yang menjadi penanda bagusnya mutu pendidikan di suatu perguruan tinggi adalah karena tingkat penerimaan kerja yang tinggi. Ini menjadi penanda bahwa perguruan tinggi memang lulusannya banyak dibutuhkan oleh dunia kerja saat ini.

Sebagai perguruan tinggi Islam yang ingin mencetak sarjana yang kader, tentunya juga menemukan kendala dalam menjalankan proses pengkaderan yang seringkali mengancam, yaitu media sosial yang bebas nilai menjadi ancaman bagi mahasiswa, mereka bisa mengakses apapun dan berinteraksi dengan siapapun. Dengan penggunaan internet, pesantren menghadapi tantangan serius yaitu "kampung global" (global village), di mana dunia dengan adanya media elektronik public yang pada zaman dahulu dikenal dengan radio dan tv telah menyempit begitu rupa selayaknya sebuah kampung besar (Marshal, 1962).

Selain itu juga kota Surabaya sebagai kota metropolitan yang mempunyai budaya "open" tidak lepas dari tempat-tempat maksiat didalamnya. Ketika gaya hidup global ini memunculkan perubahan nilai dan mempengaruhi masyarakat lain, maka akan terjadi pergeseran nilai dalam masyarakat penerima pengaruh (Waters, 1994).

Dari analisis internal dan eksternal untuk mencapai tujuan pengkaderan, maka ada beberapa tahapan-tahapan program yang harus diikuti oleh mahasiswa untuk membentuk mereka menjadi kader yang militan. Sebagaimana di STAI Luqman AlHakim waktu belajar adalah 4 tahun, maka tahapan pengkaderan juga di bagi menjadi 4 tahapan, yaitu di tahun pertama, ke-dua, ke-tiga dan ke-empat, yang mana masingmasing tahun tersebut ada target dan penekanan karakter yang diharapkan.

Tahun pertama atau semester I dan II, mereka ditempatkan di kampus II yang terletak di atas Bukit gunung Kapur Kukusan, Panceng Gresik Jawa Timur. Adapun dalam aspek pengkaderan, kegiatan di asrama didesain untuk mengikis rasa togho (sombong). Karena ini sebagai cara untuk membersihkan hati. Hati yang bersih dari sifat sombong akan mudah menghambakan diri kepada Allah SWT. Diantara kegiatan tersebut adalah mahasiswa diminta mencari kayu bakar, mengangkut air di musim kemarau untuk kebutuhan sehari-hari. Hal ini juga menumbuhkan sifat mereka untuk siap dipimpin. Pemurnian tauhid lewat pengikisan rasa sombong tersebut sesuai dengan muatan sitematika wahyu dari wahyu yang pertama, yaitu QS. Al-Alaq ayat 15 .

Menurut (Hasyim, 2010) Intisari studi (dirasah) surah al-'Alaq : 1-5 adalah penempatan posisi Rabb dan kedudukan al-insan secara proporsional. Allah adalah sebagai subyek (Pencipta, Maha Mulia, Maha Pandai) dan manusia sebagai obyek. Awal sebuah kerusakan (chaos) terjadi di dunia ini ketika manusia tidak bersedia menerima dirinya sebagai obyek, bahkan memposisikan dirinya sebagai subyek. Makhluk memposisikan diri seperti al-Khaliq. Hina tetapi merasa diri mulia, masih memerlukan pujian dan sanjungan. Hanya memiliki ilmu sedikit (wa ma utitum minal 'ilmi ila qalilan), dipinjami kekuasaan, menolak aturan Tuhan Yang Maha Mengetahui (al-'Alim) dan Maha Mulia (al-Akram).

Secara kognitif mereka fokus pada penguatan tahsin dan tahfidz, dimana untuk tahfidz ini ditargetkan hafal minimal 2 juz. Hal ini menjadikan mereka selalu dekat dengan al-Qur'an. Kemudian juga dibekali dengan mata kuliah untuk penguatan berbahasa asing, khususnya bahasa Arab yang menggunakan kitab Baina Yadaik. Selain 
itu juga diajarkan fiqih ibadah untuk memastikan ibadah mereka benar. Karena latar belakang mereka yang beragam, maka perlu adanya matrikulasi.

Ditahun pertama mahasiswa banyak konsentrasi pada tahsin dan tahfidzul Qur'an ini menjadikan mereka sering berinteraksi dengan Al-Qur'an. Dengan AlQur'an maka diharapkan mahasiswa mempunyai akhlaq qur'ani. Hal ini sesuai dengan muatan sitematika wahyu yang ke-dua, yaitu QS. Al-Qalam ayat 1-7. Menurut (Hasyim, 2010) bahwa sesungguhnya Nabi Muhammad saw. melaksanakan Al-Qur'an baik perintahnya maupun larangannya telah menjadi sikap hidup dan melekat di tabi'at aslinya. Perintah Al-Qur'an dikerjakan, larangannya ditinggalkan. Semuanya dihiasi oleh budi pekerti yang agung, mulia, dermawan, berani, pemaaf, menahan amarah. Pendeknya semua budi yang indah.

Pada tahun kedua, yaitu pada semester III dan IV, mahasiswa dipindahkan ke kampus I di Surabaya. Secara kognitif sudah mendapatkan mata kuliah-mata kuliah keprodian, yaitu dibagi menjadi beberapa prodi, yaitu: MPI, KPI, Eksya, dan PGMI. Selain itu juga mereka mendapatkan pelajaran kitab-kitab gundul dan sebagai mata kuliah penunjangnya adalah nahwu shorof untuk bisa membaca kitab.

Dalam kehidupan berasrama, aspek ibadah sangat ditekankan. Mulai dari sholat malam, sholat 5 waktu, halaqah tahfizh, dzikir pagi, petang dan malam serta ibadah sunnah lainnya. Aktifitas ibadah tersebut diabsen setiap hari yang bagi yang tidak hadir akan dikenakan konsekuensi logis. Pembiasaan ibadah dalam kehidupan di asrama tersebut sesuai dengan muatan sitematika wahyu dari wahyu yang ke-tiga, yaitu QS. Al-Muzammil ayat 1-10.

Menurut Shihab (2012) tujuan utama QS. Al-Muzammil ayat 1-10 adalah bimbingan kepada Nabi Muhammad SAW. dan juga umat Islam agar menyiapkan mental untuk melaksanakan tugas penyampaian risalah dengan segala rintanganrintangannya, sekaligus ancaman kepada para pengingkar kebenaran. Surat ini juga bertujuan mengingatkan bahwa amal-amal kebajikan menampik rasa takut dan menolak marabahaya, serta meringankan beban, khususnya bila amal kebajikan itu berupa kehadiran kepada Allah SWT. serta konsentrasi mengabdi kepada-Nya pada kegelapan malam.

Selain itu, mereka ditugaskan ke unit-unit amal usaha organisasi, yang meliputi: yaitu program sosial mengajar ngaji anak-anak jalanan di pinggiran kota Surabaya yang masuk dalam program Pusat Pendidikan Anak Sholeh (PPAS), mengajar TPQ di beberapa tempat sekitar kampus, kemudian di ketakmiran, di guest house yayasan, di Unit Pelaksana Zakat (UPZ) dan di kepengasuhan SMP-SMA Luqman Al-Hakim Surabaya. Di unit-unit amal usaha inilah mahasiswa belajar di sektor informal yang jelas struktur organisasinya, jelas fasilitas dan sarana prasarana dan wilayah tanggung jawabnya.

Disini mahasiswa belajar untuk mengaktualisasikan ilmu yang telah diperoleh dari proses pembelajaran yang telah dan sedang dilalui di STAI Luqman Al Hakim Surabaya. Diantara kegiatan mahasiswa di departemen-departemen adalah dakwah di masyarakat lewat mengajar TPA dan membina anak-anak jalanan di pinggiran kota surabaya serta menjadi pengasuh santri SMP dan SMA dan tugas lain sebagai implementasi dari nilai-nilai keimanan. Hal ini dengan sesuai dengan muatan sitematika wahyu dari wahyu yang ke-empat, yaitu QS. Al-Muddatstsir ayat 1-7. Dalam QS. Al-Muddatstsir ayat 1-7 mengandung perintah kepada Nabi Muhammad 
SAW untuk melaksanakan dakwah mengajak kaumnya untuk beribadah kepada Tuhan-Nya (Fuad, 2012).

Adapun di tahun ketiga, semester V dan VI secara kognitif melanjutkan perkuliahan keprodian dan diniyah. Adapun kegiatan pengkaderan di tahun ketiga ini mereka masuk dalam jajaran pengurus Badan Eksekutif Mahasiswa (BEM) dan kepengurusan asrama. Disini mereka belajar tentang bagaimana mengelola tim atau anak buah, menggerakkan serta menginstruksikan mereka dalam sebuah program, memimpin rapat, dan mengikuti kegiatan di dalam dan di luar kampus. Dalam struktur organisasi BEM, ada presiden dan menteri-menteri yang disesuaikan dengan kebutuhan kampus dan asrama. Untuk menguatkan itu didukung juga dengan mata kuliah managemen event, yaitu mata kuliah yang mengajarkan kepada mereka bagaimana membuat kegiatan, karena dalam dunia haroki, ukuran sukses itu kalau bisa menggelar acara-acara yang mendatangkan banyak jamaah.

Berorganisasi akan memberikan ruang kepada mahasiswa untuk dapat berkreasi dan beraktivitas secara lebih luas. Mahasiswa akan banyak berinteraksi dengan orang lain yang berlatar belakang berbeda-beda. Disinilah kemampuan komunikasi dan emosi (emotional quotient) mahasiswa akan terlatih dalam menghadapi berbagai persoalan dan konflik yang terjadi. Ada beberapa manfaat organisasi bagi mahasiswa yaitu melatih leadership, belajar mengatur waktu, memperluas jaringan atau networking, mengasah kemampuan sosial, problem solving dan manajemen konflik (Pertiwi dkk, 2014).

Berorganisasi artinya suatu entitas yang hidup bersama dalam dalam ikatan jama'ah dengan aturan dan tujuan tertentu. Organisasi kemahasiswaan dibentuk adalah sebagai sarana mahasiswa belajar memimpin dan dipimpin dalam sebuah jama'ah Islam. Dengan kuatnya jama'ah Islam, maka peradaban Islam akan terbangun. Hal ini dengan sesuai dengan muatan sitematika wahyu dari wahyu yang ke-empat, yaitu QS. Al-Fatihah ayat 1-7.

Menurut Mujtahid (2016) apa yang menjadi cita-cita Islam sesungguhnya telah diterangkan secara utuh, holistik dan komprehensif dalam ummul kitab, yaitu surah alFatihah. Surat al-Fatihah memuat saripati ajaran Islam yang benar-benar memiliki misi universalitas dan iklusivitas yang mengajak umatnya agar mendapat petunjuk dan kasih sayang-Nya. Sulit diingkari bahwa ajaran pokok Islam, seperti yang terkandung surat al-Fatihah merupakan jalan yang lurus, petunjuk yang menjadi pegangan sekaligus haluan hidup manusia.

Di tahun ke-empat, atau semester VII sampai VIII, mahasiswa secara kognitif sudah konsentrasi pada tugas akhir, yaitu: pengerjaan skripsi, persiapan ujian baca kitab, dan ujian tahfidz 5 juz. Sehingga mahasiswa dibebaskan dari tugas-tugas unit amal usaha. Mereka juga mendapatkan pembekalan marhalah ula, yaitu pemahaman materi dasar sistematika wahyu untuk bekal mereka tugas di daerah-daerah nantinya.

Kalimat konsep (manhaj) sistematika nuzulnya wahyu merupakan terminologi yang dipakai oleh Ust. Abdullah Said (pendiri pesantren hidayatullah) dengan maksud suatu rancangan, ide, dan gagasan untuk mengulangi kembali kejayaan yang pernah diraih Rasulullah bersama para sahabat dan pengikut beliau dalam mendakwahkan Islam, karena pola pembinaannya merujuk pada tata urutan wahyu yang turun pertama kali (tartibun nuzul). Dengan kata lain konsep sistematika nuzulnya wahyu adalah suatu upaya merekonstruksi nilai-nilai Al-Qur'an secara sistematis sebagaimana 
yang dilakukan Rasul dan para sahabatnya dalam mengemban dakwah Islam (Thohari, 2000)

Selain tahapan-tahapan pengkaderan yang harus dilalui mahasiswa selama 4 tahun, ada juga kegiatan-kegiatan penunjang sebagai strategi membangun kader militan di STAI Luqman Al Hakim Surabaya, yaitu: melibatkan tokoh-tokoh senior lembaga untuk memberikan spirit perjuangan, mengikutkan mahasiswa dalam aksiaksi sosial melawan kedzoliman, mengkontekstualkan situasi saat ini dalam perkuliahan dan pembelajaran agar mahasiswa selalu mempunyai motivasi yang membara, memasukkan mata kuliah metolodologi ber-Islam yang memuat tentang sistematika wahyu. Mengajarkan mata kuliah wawasan pergerakan, diantaranya dengan mengundang beberapa pimpinan beberapa organisasi massa Islam, supaya mahasiswa mengetahui posisi dimana Hidayatullah.

Strategi membangun kader diatas sesuai dengan artikel yang ditulis oleh Muhammad Rusydi yang berjudul: Memaknai Pengkaderaan Sebagai Jantungnya Organisasi, bahwa pengkaderan bukan hanya berisi tentang outbond dan kerjasama tim, namun yang esensial adalah mengubah paradigma berpikir, memperkuat intelektualitas, memperkuat karakter, mental dan spiritualitas, memperkuat jasad/kesehatan, memperkuat managerial (Rusydi, 2014)

Untuk mencetak kader yang militan, mahasiswa wajib tinggal di asrama dengan aturan dan tata tertib mahasiswa. Aturan dan tata tertib mahasiswa dibuat bersifat preventif dan diagnostik. Preventif artinya mengurangi atau menghilangkan kejadian yang tidak diinginkan, sedangkan diagnostik artinya mengidentifikasi permasalahan mahasiswa, yaitu dengan pemanggilan dan tausyiyah. Salah satu konsekuensi dari tinggal di asrama adalah setiap mahasiswa harus selalu mengikuti aturan perilaku yang telah ditetapkan, baik terpaksa ataupun sukarela (Al Baqi dkk, 2017).

Pengawasan dan evaluasi dilaksanakan dengan penegakan aturan dan tata tertib. Dalam menegakkan aturan menggunakan pendekatan andragogik atau pendekatan orang dewasa. Terlihat dari pemberian konsekuensi logis diganti namanya dengan amal sholeh, dengan filosofi derdasarkan hadist nabi: "Dan ikutilah perbuatan dosa dengan perbuatan baik, niscaya ia akan mengahapuskannya" (HR. Tirmidzi).

Evaluasi strategi pengkaderan STAI Luqman Al-Hakim - Pesantren Hidayatullah Surabaya terhadap lahirnya kader organisasi militan di Hidayatullah

Kader STAI Luqman Al-Hakim disiapkan untuk menjadi kader penerus estafeta kepemimpinan umat, khususnya di organisasi Hidayatullah, diharapkan mereka menjadi leader yang bisa membawa umat ke arah yang lebih baik. Mereka juga dididik untuk profesional, yaitu menjadi ahli dibidangnya masing-masing. Prodi MPI diharapkan mampu menjadi pengelola lembaga pendidikan, sebagai peneliti pendidikan. Sedangkan di Prodi PGMI mampu menjadi pengelola atau pendidik di Madrasah Ibtidaiyah/SD. Sedangkan di Prodi Eksya menjadi pengelola lembaga ekonomi syari'ah, menjadi penggerak potensi ekonomi umat dan sebagai pengamat ekonomi. Sedangkan di Prodi Dakwah atau KPI mampu berdakwah di mimbarmimbar, berdakwah secara on line maupun off line, menjadi penggerak dakwah di masjid- masjid, menjadi peneliti dakwah serta ahli-ahli jurnalistik. Bergerak di profesi manapun alumni STAI Luqman Al-Hakim nanti, hal yang harus ada dalam diri mereka adalah menjadi kader dan leader bagi umat. 
Ukuran kader berhasil bukan dilihat dari amanah yang diterima di organisasi Hidayatulah. Sebaliknya alumni bisa dikatakan gagal, jika tidak bisa menjalankan tugas dengan amanah. Alumni wajib mengabdi di organisasi Hidayatullah setelah dinyatakan lulus dari STAI Luqman Al-Hakim minimal 5 tahun. Bagi alumni yang masa pengabdiannya belum sampai 5 tahun dan keluar dari organisasi, maka itu juga dikatakan kader gagal.

Untuk melihat hasil dari proses pengkaderan yang ada di STAI Luqman Al-Hakim Surabaya, maka perlu melihat data penyebaran dan aktifitas alumni yang telah tersebar di Indonesia. Dari data penyebaran alumni, penulis menyimpulkan bahwa alumni STAI Luqman Al-Hakim Surabaya saat ini telah terserap dan tersebar ke seluruh Indonesia untuk mengabdikan dirinya dalam perjuangan Islam dibawah naungan organisasi Hidayatullah. Diantara mereka ada yang saat ini menduduki amanah strategis yang menjadi ujung tombak organisasi Hidayatullah.

Data sebaran alumni yang telah lulus mulai angkatan tahun 1994-2014 yang berjumlah 540 alumni dilihat dari segi profesi ditemukan bahwa;

a) Sebanyak 67 alumni menjadi Kepala Sekolah SD-SMA Hidayatullah,

b) Sebanyak 166 alumni menjadi guru SD-SMA Hidayatullah,

c) Sebanyak 4 alumni menjadi ketua pimpinan wilayah Hidayatullah,

d) Sebanyak 27 alumni menjadi Kepala Sekolah SD-SMA Hidayatullah,

e) Sebanyak 127 alumni menjadi pengurus pesantren Hidayatullah,

f) Sebanyak 18 alumni menjadi wakil ketua perguruan tinggi Hidayatullah,

g) Sebanyak 15 alumni menjadi PNS dan masih tetap beraktifitas di Hidayatullah,

h) Sebanyak 13 alumni menjadi PNS dan beraktifitas di luar Hidayatullah,

i) Sebanyak 78 alumni menjadi pengelola Baitul Maal Hidayatullah (BMH),

Sedangkan dilihat dari kondisi alumni, ditemukan bahwa;

a) Sebanyak 410 sampai saat ini masih istiqomah beraktifitas dan berjuang di organisasi Hidayatullah.

b) Sebanyak 79 alumni meminta mutasi tempat tugas, tetapi tetap di cabang Hidayatullah,

c) Sebanyak 17 alumni memilih untuk beraktifitas di luar Hidayatullah atau pulang kampung tempat asalnya, dan

d) Sebanyak 9 alumni sudah meninggal.

Dari data tersebut dapat dapat disimpulkan bahwa kondisi alumni STAI Luqman Al-Hakim Surabaya sebanyak 540 orang, dikurangi yang sudah meninggal 9 orang masih ada 531 orang. Dari jumlah 531 tersebut yang kemudian memilih untuk beraktifitas di luar Hidayatullah ada 17 orang. Jadi saat ini ada 514 alumni yang tetap beraktifitas di organisasi Hidayatullah. Bisa dikatakan bahwa kader militan STAI Luqman Al-Hakim Surabaya saat ini adalah 96,8 \%. Sedangkan mereka yang kurang militan ada $3,2 \%$ saja.

Hal ini wajar, karena perjanjian di awal mahasiswa dengan lembaga STAI Luqman Al-Hakim Surabaya adalah masa pengabdian mereka setelah lulus selama 5 tahun di organisasi Hidayatullah. Selebihnya diberikan pilihan untuk tetap atau keluar dari organisasi Hidayatullah. Namun dari data yang ada mayoritas alumni tetap berjuang di Hidayatullah. Hal ini membuktikan bahwa program pengkaderan di STAI Luqman Al-Hakim Surabaya telah berhasil dengan baik.

Testimoni alumni yang diambil dari 4 alumni STAI Luqman Al-Hakim Surabaya yang bertugas di Indonesia barat, tengah dan timur. Luqman Hakim dan Sadarwadi 
yang bertugas di Medan dan lampung mewakili Sumatera atau Indonesia bagian barat. Sedangkan Fatahillah yang bertugas di kendari mewakili indonesia bagian tengah, sedangkan Haeranzi yang bertugas di Sentani-Papua mewakili Indonesia bagian timur.

Dari beberapa pernyataan alumni tersebut dapat disimpulkan bahwa kegiatan pengkaderan sangat mereka rasakan manfaatnya. Setidaknya ada 3 aspek yang dirasakan, yaitu aspek ruhiyah, kepemimpinan dan sosial. Mereka merasakan proses pengkaderan di STAI Luqman Al-Hakim sudah bagus dan perlu dipertahankan dan dan dikembangkan. Luqman Hakim yang bertugas di Medan memberikan masukan supaya kegiatan pengkaderan semakin kuat, maka pengkader sebaiknya adalah kader yang berhasil tugas di daerah, sehingga mampu mentransfer pengalamanpengalamannya ke mahasiswa. Menurut Afrizal (2008) alumni memegang peranan penting dalam memberikan masukan terhadap proses dan perbaikan bagi lembaga pendidikan itu sendiri termasuk perguruan tinggi

Sedangkan testimoni diminta dari Ustadz Abdullah Ridho selaku ketua PD Hidayatullah Bojonegoro dan Ustadz Syamsul Bahri selaku Sekretaris PW Hidayatullah Nusa Tenggara Barat. Penulis memilih ini karena beliau berdua mewakili jawa dan luar jawa. Dari testimoni keduanya didapatkan informasi bahwa pengguna alumni STAI Luqman Al-Hakim merasa puas dan bangga dengan hasil didikan STAI Luqman AlHakim. Karena mereka terbukti militan, amanah dan profesional.

Alumni STAI Luqman Al-Hakim Surabaya adalah kader Hidayatullah yang telah menginfakkan hidupnya untuk perjuangan Islam, siap hidup dan mati dalam perjuangan Islam. Hal ini ditunjukkan dengan keistiqomahan mereka untuk aktif di Hidayatullah. Ini juga menunjukkan bahwa hasil dari pengkaderan di Hidayatullah lewat STAI Luqman Al-Hakim Surabaya telah mampu mencetak kader yang militan.

\section{KESIMPULAN}

Konsep strategi perencanaan pengkaderan dimulai dengan perumusan tujuan pengkaderan sesuai dengan visi lembaga pendidikan, pola pembinaan kader terpola dalam jadwal keseharian, pekanan, bulanan, semesteran dan tahunan yang kegiatannya meliputi aspek ruhiyah, fikriyah dan jasadiyah. Untuk menghasilkan kader yang baik, maka perlu dibentuk team pengkaderan terdiri dari team akademik dan team asrama. Sedangkan strategi pelaksanaan pengkaderan perlu dilakukan langkah-langkah analisis SWOT, memperkuat spirit perjuangan, mengikutkan mahasiwa dalam aksi-aksi sosial, pembelajaran konstekstual, memasukkan materi manhaj sistematika wahyu dan materi wawasan pergerakan Islam. Tahapan pengkaderan dilakukan per-jenjang/tahun yang setiap jenjangnya dimasukkan nilai-nilai sistematika wahyu. Sistem pengawasan dengan tata tertib dan evaluasi dengan konsekuensi logis berupa amal sholeh serta sistem gugur bagi mahasiswa yang tidak bisa mengikuti proses pengkaderan. Hasil pengkaderan menunjukkan alumni telah istiqomah berjuang di organisasi. Program pengkaderan bermanfaat dalam meningkatkan aspek ruhiyah, kepemimpinan dan kepekaan sosial sehingga alumni menjadi kader yang militan, amanah dan profesional.

\section{REFERENSI}

Afrizal. (2018). Studi Pelacakan Alumni (Maju Bersama Alumni). Jambi: Fakultas Ekonomi UNJA., hlm. 6 
52 | P a g e

Cholis, Manajemen Kaderisasi dalam ...

Al Baqi, S. dkk. (2017). Faktor Pendukung Motivasi Berperilaku Disiplin Pada Santri Pondok Pesantren, Journal University of Darussalam Gontor. Vol. 01, No. 01.

Arifin, Syaiful. (2014). Kaderisasi Organisasi. Tulisan lepas disampaikan pada diklat LMMT oleh BEM STKIP PGRI Tulungagung tanggal 27 April 2014.

Fuad, MN. (2019). Studi Surah Al-Muddatstsir Tentang Bimbingan Dakwahdalam Kitab Al-Tafsir Al-Munîr Karya Wahbah Al-Zuhailî. Jurnal An-Nida'. Vol 7 No 2 . hal. 58

Harahap, SS. (2001). Analitis Kritiss Atas Laporan Keuangan, Cetakan Ketiga. Jakarta: PT Raja grafindo Persada.

Hasyim, Sholeh. (2010). Spirit Ber-Islam, Cara Cerdas Memahami dan Berkhidmat terhadap Al-Qur'an. Cetakan Pertama. Semarang: PT Pustaka Rizki Putra. Hal. 132

Kurniawan, Asep. (2016). Manajemen Strategik Pondok Pesantren dalam menyiapkan Da'i yang berkualitas. Jurnal Akademia UIN Sunan Gunung Jati Bandung.

Marshal, McLuhan. (1962). The Gutenberg Galaxy: The Making of Typographic Man, cetakan I. Toronto: University of Toronto Press. hlm. 21-31.

Mudofar, Muhlis. (2017). Strategi pembelajaran Tahfidzul Qur'an di Pondok Pesantren Darul Ulum Boyolali. [Tesis] Surakarta (ID): Institut Agama Islam Negeri Surakarta

Mujtahid. (2016). Membangun peradaban Islam yang washatan. Malang: UIN-Maliki Press. ISBN 978-602-1190-81-4 http:// repository.uin-malang.ac.id/1747/

Pertiwi, MC dkk. (2014). Hubungan Organisasi dengan Mahasiswa dalam Menciptakan Leadership. Surakarta: Jurnal PGSD FKIP Universitas Muhammadyah. ISBN: 978602-70471-1-2

Rahmawati, Rukhaini F. (2016). Kaderisasi dakwah melalui lembaga pendidikan Islam. Jurnal Manajemen Dakwah. TADBIR Vol. 1, No. 1

Rosenberg, Marc. J. (2001). E-Learning: Strategies for Delivering Knowledge In The Digital Age. USA: McGraw-Hill Companie

Rusydi, Muhammad. (2014) Memaknai pengkaderaan sebagai jantungnya organisasi. Maret 2018, pukul 14.45

Shihab, M. Quraish. (2012). Al-Lubab: Makna, Tujuan, dan Pelajaran dari Surah-Surah AlQur'an, Jakarta: Lentera Hati. hlm. 432.

Thohari, Hamim. (2000). Panduan Berislam Paket 1. Jakarta: Departemen Dakwah dan Penyiaran Hidayatullah. Cet. 1 2000. hal.17

Waters, Malcolm. (1994). Globalization. Dalam Gordon Marshall (ed). Oxford Dictionery of Sociology. New York: Oxford University Press. h. 258. 